MATEC Web of Conferences 23,01020 (2015)

DOI: $10.1051 /$ matecconf/ 20152301020

(C) Owned by the authors, published by EDP Sciences, 2015

\title{
Kinetic study of coals gasification into carbon dioxide atmosphere
}

\author{
A.G. Korotkikh ${ }^{1}$, K.V. Slyusarskiy ${ }^{1}$ \\ ${ }^{1}$ Tomsk Polytechnic University, Lenin Avenue, 30, 634050, Tomsk, Russia
}

\begin{abstract}
The solid fuel gasification process was investigated to define chemical reactions rate and activation energy for a gas-generator designing and regime optimizing. An experimental procedure includes coal char samples of Kuznetskiy and Kansko-Achinskiy deposits consequent argon pyrolysis into argon and oxidating into carbon dioxide with different temperatures. The thermogravimetric analysis data of coal char gasification into carbon dioxide was obtained in the temperature range $900-1200{ }^{\circ} \mathrm{C}$. The mass loss and gasification time dependencies from temperature were defined to calculate chemical reaction frequency factor and activation energy. Two coal char gasification physico-mathematical models were proposed and recommendations for them were formed.
\end{abstract}

\section{Introduction}

Recently, special attention is attended to the solid fuel gasification problems, especially for bituminous coals and anthracites. They could replace traditional organic fuel in cases of their combustion on power plants during heat and electrical energy generation or syngas and hydrogen production for chemical and metallurgy industries [1,2]. The solid fuel gasification application in thermal power plant would, also, allow to solve environment pollution and flue gases utilization problems appearing during traditional fuel combustion.

Thermochemical solid fuel gasification process is used to produce combustible gases $\left(\mathrm{H}_{2}, \mathrm{CO}, \mathrm{C}_{\mathrm{n}} \mathrm{H}_{\mathrm{m}}\right)$ by fuel carbon interaction with different oxidizers. Oxygen (air), water steam, carbon dioxide or their mixtures could be used as an oxidizing gaseous medium. Depending on feed gas components ratio, temperature, duration of reactions and other factors is possible to obtain different contents of syngas with preset characteristics.

The solid fuel gasification process takes place into gas-generator unit with gaseous oxidizer feed. The main heterogeneous chemical reactions are carbon with oxygen and steam reaction resulted into forming carbon mono- and dioxide as well as carbon with carbon dioxide [4]:

$$
\mathrm{C}+\mathrm{CO}_{2}=2 \mathrm{CO} \text {. }
$$

The solid fuel gasification and heterogeneous reactions of carbon with carbon dioxide research is important because this reaction is directly connected with carbon-oxygen and carbon-steam heterogeneous reactions [4]:

$$
\begin{gathered}
\mathrm{C}+\mathrm{O}_{2}=\mathrm{CO}_{2}, \\
\mathrm{C}+\mathrm{H}_{2} \mathrm{O}=\mathrm{CO}+\mathrm{H}_{2}, \\
\mathrm{C}+2 \mathrm{H}_{2} \mathrm{O}=\mathrm{CO}_{2}+2 \mathrm{H}_{2} .
\end{gathered}
$$

The thermal analysis results for three coal chars from Kuznetskiy and Kansko-Achinskiy deposits obtained into carbon dioxide in the temperature range $900-1200{ }^{\circ} \mathrm{C}$. The samples mass loss rate, gasification time, activation energy of heterogeneous carbon oxidation reaction were defined. Two coal char gasification physico-mathematical models allowing to calculate heterogeneous reactions rate and gasification time depending from temperature and coal quality were proposed. 


\section{Experimental procedure}

\subsection{Coal char samples preparation}

Powder with fraction $80 \mu \mathrm{m}$ of different coals with different carbon content was used as a solid fuel sample into experiments.

The carbon content into initial solid fuel samples was defined by maximal mass loss during sample heating into oxidizing medium. Solid fuel samples density was measured by picnometric method. The densities and content of carbon of solid fuel samples are presented in Table 1.

Table 1. Densities and carbon content of solid fuel samples

\begin{tabular}{|l|l|l|l|}
\hline Solid fuel sample & Specific density, $\mathrm{kg} / \mathrm{m}^{3}$ & Bulk density, $\mathrm{kg} / \mathrm{m}^{3}$ & $\begin{array}{l}\text { Carbon content, wt. } \\
\%\end{array}$ \\
\hline Anthracite & $1753 \pm 56$ & $339 \pm 2$ & 89 \\
\hline Bituminous coal & $1927 \pm 15$ & $340 \pm 6$ & 74 \\
\hline Lignite & $1425 \pm 10$ & $347 \pm 13$ & 66 \\
\hline
\end{tabular}

\subsection{Thermal analysis}

Before thermal analysis the solid fuel samples were undergo pyrolysis into argon during SNOL $30 / 1100$ furnace heating with rate $50{ }^{\circ} \mathrm{C} / \mathrm{min}$ till $1000^{\circ} \mathrm{C}$ to obtain coal char, remove water and volatiles from fuel. Fuel samples $20 \mathrm{~g}$ of mass were put into ceramic crucible and held into furnace for 1 hour, and then they were cooled to $400{ }^{\circ} \mathrm{C}$.

The $20 \mathrm{mg}$ coal char samples thermal analysis was made using simultaneous TG-DSC analyzer Netzsch STA 449 F3 Jupiter. The coal char samples were heated into furnace into argon atmosphere with rate $50{ }^{\circ} \mathrm{C} / \mathrm{min}$ to $900,1000,1100$ and $1200^{\circ} \mathrm{C}$. The argon flow rate was $10 \mathrm{ml} / \mathrm{min}$. After reaching preset temperature inert gaseous medium was replaced by carbon dioxide mixture with argon with $24 / 1$ ratio and flow rate $250 \mathrm{ml} / \mathrm{min}$. The coal char samples isothermal soaking time vary from 60 to 120 min. depending on furnace temperature.

\section{Results and discussion}

\subsection{Effect of temperature}

Three parallel simultaneous TG-DSC analyzer measurements were made for each coal char sample with different furnace temperature values into carbon content medium. The sample thermogravimetric measurement results are presented in Fig. 1.

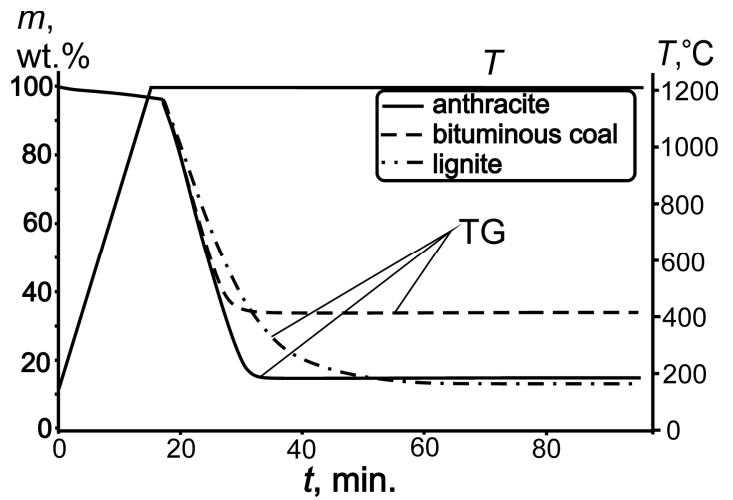

a)

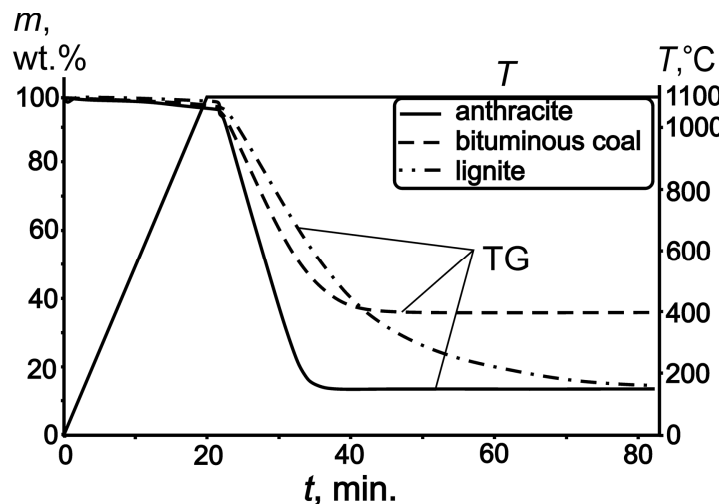

b) 


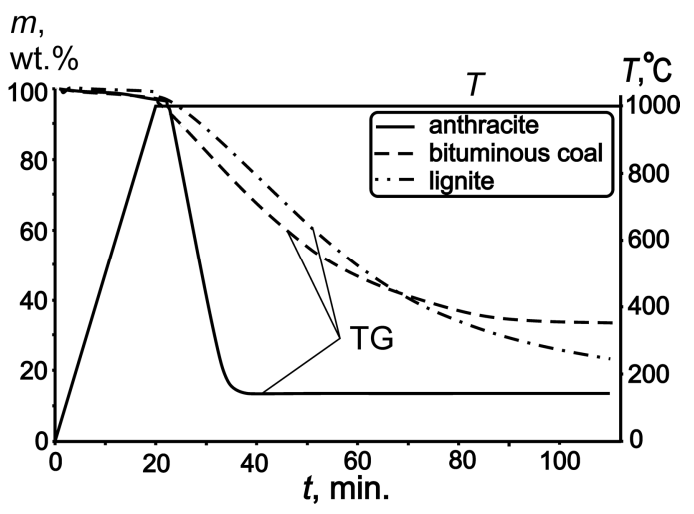

c)

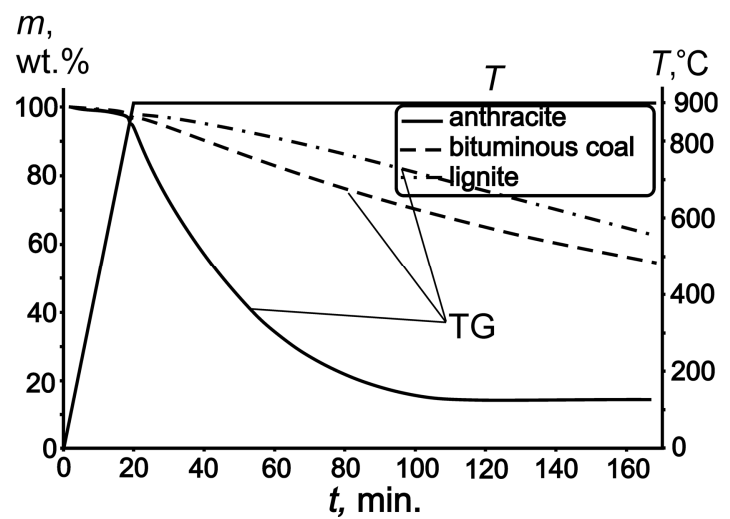

d)

Fig. 1 - TG-curves of coal char samples at temperature: $1200{ }^{\circ} \mathrm{C}(a) ; 1100{ }^{\circ} \mathrm{C}(b) ; 1000{ }^{\circ} \mathrm{C}(c)$ and $900{ }^{\circ} \mathrm{C}(d)$

Mass loss during char samples heating to preset temperature into argon was 2-4\% from initial mass depending on fuel quality. While carbon dioxide feed into furnace the carbon oxidation endothermic reactions were observed with $60 \%$ mass loss for bituminous coal and 82-83\% for anthracite and lignite.

As carbon dioxide temperature into furnace increases the sample gasification time decreases and mass loss and chemical reaction rate rises. According to Arrhenious equation [5] fuel mass loss rate during heterogeneous carbon oxidation rate could be defined as:

$$
v=A_{0} \exp \left(-E_{a} / R T\right),
$$

where $v$ - mass loss rate, $\mathrm{kg} / \mathrm{s} ; A_{0}-$ frequency factor, $\mathrm{kg} / \mathrm{s} ; E_{a}-$ activation energy, $\mathrm{J} / \mathrm{mol} ; R-$ gas constant, J/(kg K); $T$ - temperature, $\mathrm{K}$.

The carbon oxidation reaction activation energy and frequency factor for coal char samples into carbon dioxide within temperature range $900-1200{ }^{\circ} \mathrm{C}$ were defined. The values of obtained constants are presented in Table 2 .

Table 2. The activation energy and frequency factor of carbon oxidation for coal char samples

\begin{tabular}{|l|c|c|c|}
\hline \multirow{2}{*}{ Parameters } & \multicolumn{3}{|c|}{ Kinetic constants value for } \\
\cline { 2 - 4 } & Anthracite & Bituminous coal & Lignite \\
\hline$E_{a}, \mathrm{~kJ} / \mathrm{mol}$ & 64 & 148 & 151 \\
\hline$A_{0}, \mathrm{~kg} / \mathrm{s}$ & 0.0052 & 4.9324 & 5.1801 \\
\hline
\end{tabular}

Obtained activation energies and frequency factors via equation 1 for solid fuel samples is in good agreement with presented into literature data for high and low-quality coals [6,7]. The analysis of defined constants shows that carbon content into solid fuel and coal char increasing causes activation energy and frequency factor decreasing. This means that high-quality gasification rate strongly depends on gaseous medium temperature. Growing ash content leads to mass loss rate on gasification temperature decreasing.

\section{Gasification mathematical model}

Two physico-mathematical models were proposed for coal char gasification into ceramic crucible process into furnace description:

1. one dimensional heat transfer equation based model with moving border between two substances - coal char and ash, appearing after sample gasification: 


$$
\begin{aligned}
& \text { for } x \in\left(0 ; x_{g r}\right): \quad \rho_{C} c_{p C} \frac{\partial T}{\partial \tau}=\lambda_{C} \frac{\partial^{2} T}{\partial x^{2}}, \\
& \text { for } x \in\left(x_{g r} ; x_{0}\right): \quad \rho_{A} c_{p A} \frac{\partial T}{\partial \tau}=\lambda_{A} \frac{\partial^{2} T}{\partial x^{2}},
\end{aligned}
$$

2. one dimensional heat transfer equation based model with volumetric heat effect:

$$
\text { for } x \in\left(0 ; x_{0}\right): \quad \rho(C) c_{p}(C) \frac{\partial T}{\partial \tau}=\lambda(C) \frac{\partial^{2} T}{\partial x^{2}}+q_{w},
$$

here $T$ - temperature, $\mathrm{K} ; \tau$ - time, s; $\rho$ - density, $\mathrm{kg} / \mathrm{m}^{3} ; c_{p}$ - heat capacity, $\mathrm{J} /(\mathrm{kg} \mathrm{K}) ; \lambda-$ conductivity, $\mathrm{W} /(\mathrm{m} \mathrm{K}) ; q_{w}$ - reaction heat effect value, $\mathrm{W} / \mathrm{m}^{3} ; C$ - carbon content, wt. $\%$. Variables with subscript «C» refers to coal char while variables with subscript «A» refers to ash.

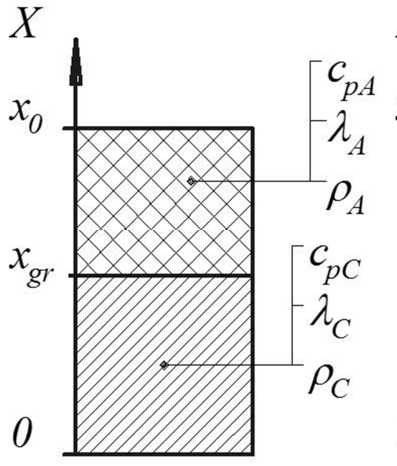

a)

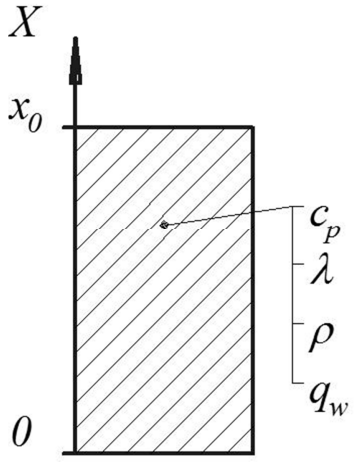

b)

Fig. 2. Scheme for numerical models: $a$ ) model with moving border; $b$ ) model with volumetric heat effect

On the bottom of the crucible the symmetry condition $\left(2^{\text {nd }}\right.$ type border condition $)$ was set, on the top $3^{\text {rd }}$ type border condition. On the border between substances the $4^{\text {th }}$ type border condition with thermal effect was set (for $2^{\text {nd }}$ model this contition is not used).

$$
\begin{aligned}
& x=0 ; \quad \frac{\partial T}{\partial x}=0, \\
& x=x_{0} ; \quad-\lambda_{A} \frac{\partial T}{\partial x}=\alpha\left(T-T_{e}\right), \\
& x=x_{g r} ; \quad-\lambda_{C} \frac{\partial T}{\partial x}=-\lambda_{A} \frac{\partial T}{\partial x}+q_{r},
\end{aligned}
$$

where $q_{r}=14.2 \cdot A_{0} \exp \left(-E_{a} / R T\right) / S-$ gasification reaction heat effect, $\mathrm{W} / \mathrm{m}^{2}[8,9] ; S-$ reaction surface (crucible cross-section area), $\mathrm{m}^{2} ; \alpha$ - heat-transfer coefficient, $\mathrm{W} /\left(\mathrm{m}^{2} \mathrm{~K}\right) ; T_{e}-$ ambient temperature, $\mathrm{K}$.

While models development the following assumptions were made:

1. The thermal properties of coal char and ash are constant.

2. Samples porosity is not taking into account.

3. Heat effect appears only at border between substances (this is not used for $2^{\text {nd }}$ model).

4. Initial temperature field inside coal char is homogeneous, coal char temperature is equal to isothermal soaking temperature.

5. All carbon of initial coal is preserved in coal char. 
Differential equations in mathematical model were solved by finitedifference method by running with implicit scheme. The char-ash moving border into $1^{\text {st }}$ model were described by timestep defining to combine it with point into dimensional lattice - equation 2:

$$
\tau=h S\left(\rho_{C}-\rho_{A}\right) /\left(A_{0} \exp \left(-E_{a} / R T\right)\right),
$$

where $h$-dimensional step, $\mathrm{m}$.

Heat effect into $2^{\text {nd }}$ model was defined using equation 3 :

$$
q_{w}=Q_{r} A_{0} \exp \left(-E_{a} / R T\right) / S / R_{0},
$$

where $Q_{r}$ - carbon oxidation chemical reaction heat effect, $14.17 \mathrm{MJ} / \mathrm{kg}$ [3]; $R_{0}$ - sample layer height, m.

Experimental and calculated data comparison results for $1^{\text {st }}$ model are presented in Fig. $3 a$, for $2^{\text {nd }}$ model - Fig. $3 b$.

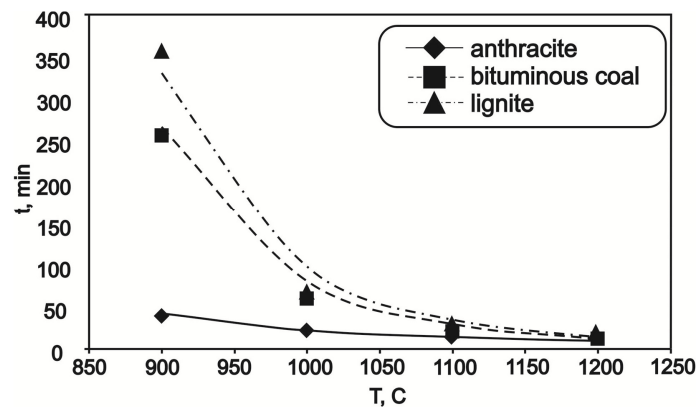

a)

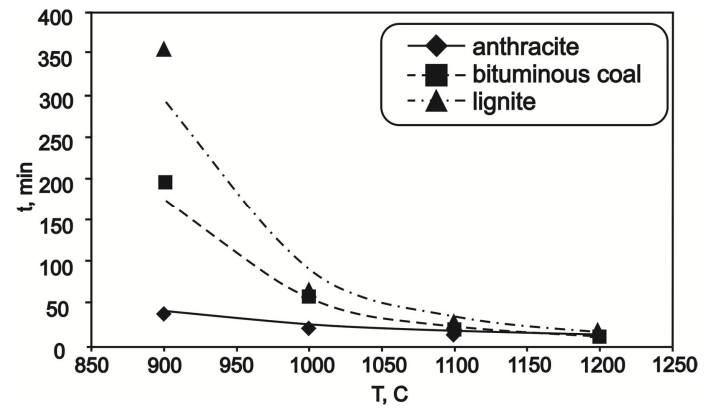

b)

Fig. 3. Coal char gasification time comparison depending on carbon dioxide temperature (line - calculation results, points - experimental results): $a-1^{\text {st }}$ model; $b-2^{\text {nd }}$ model

For data comparison, calculated and experimental coal char gasification time and relative deviation are presented in Table 3.

Table 3. Coal char calculated and experimental gasification time values

\begin{tabular}{|l|c|c|c|c|}
\hline \multirow{2}{*}{ Coal char } & \multicolumn{4}{|c|}{ Gasification time, min. at temperature } \\
\cline { 2 - 5 } & $900{ }^{\circ} \mathrm{C}$ & $1000{ }^{\circ} \mathrm{C}$ & $1100{ }^{\circ} \mathrm{C}$ & $1200{ }^{\circ} \mathrm{C}$ \\
\hline \multicolumn{5}{|c|}{ Anthracite } \\
\hline Experiment & 39.8 & 22.9 & 15.4 & 10.4 \\
\hline $1^{\text {st }}$ model & 42.5 & 21.6 & 13.9 & 9.5 \\
\hline $\begin{array}{l}\text { Relative } \\
\text { deviation, \% }\end{array}$ & 6.35 & 6.02 & 9.74 & 8.95 \\
\hline $2^{\text {nd }}$ model & 40.4 & 24.4 & 17.4 & 11.0 \\
\hline $\begin{array}{l}\text { Relative } \\
\text { deviation, \% }\end{array}$ & 6.40 & 6.00 & 10.80 & 8.90 \\
\hline \multicolumn{5}{|c|}{ Bituminous coal } \\
\hline Experiment & 195.0 & 45.5 & 17.4 & 8.9 \\
\hline $1^{\text {st }}$ model & 203.2 & 61.6 & 22.3 & 9.2 \\
\hline $\begin{array}{l}\text { Relative } \\
\text { deviation, \% }\end{array}$ & 4.04 & 26.14 & 21.97 & 3.26 \\
\hline $2^{\text {nd }}$ model & 173.0 & 53.5 & 20.1 & 8.9 \\
\hline $\begin{array}{l}\text { Relative } \\
\text { deviation, \% }\end{array}$ & 11.28 & 14.95 & 13.43 & 0.00 \\
\hline \multicolumn{5}{|c|}{ Lignite } \\
\hline
\end{tabular}




\begin{tabular}{|l|c|c|c|c|}
\hline Experiment & 355.0 & 67.0 & 28.0 & 15.0 \\
\hline $1^{\text {st }}$ model & 330.0 & 97.7 & 34.6 & 14.1 \\
\hline $\begin{array}{l}\text { Relative } \\
\text { deviation, \% }\end{array}$ & 7.04 & 31.42 & 19.08 & 6.00 \\
\hline $2^{\text {nd }}$ model & 292.4 & 87.9 & 32.1 & 13.9 \\
\hline $\begin{array}{l}\text { Relative } \\
\text { deviation, \% }\end{array}$ & 17.63 & 23.78 & 12.77 & 7.33 \\
\hline
\end{tabular}

It is seen that the highest deviation from experimental values bituminous coal and lignite gasification time is connected with temperatures $1000{ }^{\circ} \mathrm{C}$ and $1100{ }^{\circ} \mathrm{C}$. In [10] was stated, that under such conditions for carbon gasification process diffusion into pores rate is becoming limiting.

\section{Conclusions}

1. Coal char gasification process for Kuznetskiy and Kansko-Achinskiy anthracite, bituminous coal and lignite into carbon dioxide at temperatures 900, 1000, 1100 and $1200{ }^{\circ} \mathrm{C}$ was investigated using TG-DSC Netzsch Jupiter F3. The activation energy and frequency factor for each process were defined for coal char samples using experimental data via the $1^{\text {st }}$ order Arrhenius equation.

2. Two physico-mathematical models of coal samples gasification into ceramic crucible: model with moving border and model with volumetric heat effect. Proposed models were verified using experimental data. It had been found, that model with volumetric heat effect allows to obtain results with lesser relative deviation from experiment.

3. Modeling results analysis showed that the lowest relative deviation from experimental data were obtained for anthracite char samples as the maximal relative deviation for bituminous coal and lignite chars more in 1.5-2 times (10\% for anthracite us 15 and $24 \%$ for bituminous coal and lignite respectively). Also, it was defined, that the most accurate result for all coals was obtained for low temperature $-900{ }^{\circ} \mathrm{C}$. With high process temperature $-1200{ }^{\circ} \mathrm{C}-$ model with moving border is preferable.

The work is made in "National Research Tomsk Polytechnic University" under the federal target program "Research and development in priority areas of scientific and technological complex of Russia for 2014-2020", unique identifier R\&D RFMEFI58114X0001.

\section{References}

1. Sulimov D.D. Thermal eng., 2, 27 (2010)

2. Roberts D. G., Hodge E. M., Harris D. J., Stubington J. F. Energy Fuels, 24, 5300 (2010)

3. Kim S. K., Park C. Y., Park J. Y., Lee S., Rhu J. H., Han M. H., Yoon S. K., Rhee Y. W. // J. of Ind. and Eng. Chem, 20, 356 (2014)

4. Gremyachkin V.M. Comb., Exp., and Shock waves, 49, 536 (2013)

5. V.V. Pomerantsev Basics of practical combustion theory. 78 (1986)

6. $\quad$ Adánez J., Miranda J.L., Gavilan J.M. Fuel, 64, 801 (1985)

7. Liu G., Tate A.G., Bryant G.W., Wall T.F. Fuel, 79, 1145 (2000)

8. He W., He R., Cao L., Ito T., Suda T., Sato J. Comb. Sc. and Tech. 184, 2084 (2014)

9. $\quad$ Everson R. C., Neomagus H.W.J.P., Kaitano R. Fuel, 90, 2347 (2011)

10. R.-G. Kim, C.-W. Hwang, C.-H. Jeon Applied Energy, 129, 299 (2014) 